МІРОШНИК М. А., доктор технічних наук, професор (Український державний університет залізничного транспорту),

КОРОЛЬОВА Я. Ю., канд. техн. наук, доцент (Національний технічний університет «Харківський політехнічний інститут»)

\title{
Ітераційні алгоритми компонування в конструкціях мультимедіа
}

На основі теоретичного узагальнення $і$ робіт у галузі алгоритмізації типових задач конструкторського проектування в автоматизованих системах розроблено ітераційний алгоритм компонування елементів у конструкціях мультимедіа. Як формальну математичну модель використано теорію графів, де кожному конструктивному елементу схеми відповідає вершина, а електричним зв'язкам - ребра графа. Все це дає змогу абстрагуватися від конкретних електричних схем і переходити до їхніх математичних моделей - графів, розробляти ефективні методи пошуку оптимальних конструктивних рішень.

Ключові слова: електрична схема, алгоритм, ітерація, мультиграф, розбивання графа, матриця суміжності, оптимальність.

\begin{abstract}
Постановка проблеми
У зв'язку з великим різноманіттям конструктивних елементів у мультимедіа, виникає потреба визначення оптимального набору цих елементів для кожного конкретного класу схем. При цьому розробники стикаються із завданням розподілу елементів схеми по комутаційних платах з урахуванням мінімізації числа міжмодульних зв'язків, що дасть можливість підвищити надійність схеми, зменшити час затримки сигналу в ланцюгах, спростити конструкцію i підвищити технологічність пристрою в цілому $[1,2]$. Для вирішення поставлених завдань використовують алгоритми компонування, які умовно можна розбити на п'ять груп: алгоритми, що використовують методи цілочисельного програмування (дозволяють отримати точне розв'язання задачі, проте не реалізуються обчислювальною технікою); послідовні алгоритми компонування [2]; ітераційні алгоритми (оптимізація компонування елементів досягається перестановкою вершин графа з різних частин підграфа за наявності виконання умов); змішані алгоритми (спочатку виконується послідовний алгоритм 3 наступним використанням ітераційного); алгоритми, побудовані на методі гілок і меж [1-3].
\end{abstract}

\begin{tabular}{l}
\hline Аналіз останніх досліджень і публікацій \\
\hline \multicolumn{1}{c}{ Аналіз робіт у у галузі алгоритмізації } \\
конструкторського проектування дає \\
перетворювати електричні схеми в мультиграфи і \\
огляду на обмеження на максимальну \\
зв'язків колькість \\
зовнішніх зв' язків, кількість вершин у підграфі та
\end{tabular}

() М. А. Мірошник, Я. Ю. Корольова, 2019 кількість підграфів виконувати розбивання заданих графів, що дасть можливість спростити роботу компонування конструктивних елементів $[4,5]$.

Формулювання цілей: метою статті $\epsilon$ пошук оптимального розбивання графа за критерієм мінімуму зовнішніх зв'язків, кількістю підграфів та кількістю вершин у підграфах за допомогою ітераційного алгоритму, що значно підвищить надійність схеми.

\section{Основна частина дослідження \\ Задача ітераційних алгоритмів компонування полягає у виборі деякого початкового розбивання графа з подальшими перестановками вершин чи груп із одного підграфа в інший 3 метою мінімізації кількості зовнішніх ребер чи максимізації кількості внутрішніх ребер. Залежно від початкового варіанта розбивання ці алгоритми можуть бути двох типів. \\ В алгоритмах першого типу спочатку проводять початкове розбивання вихідного графа $G(X, U)$ (вручну чи за допомогою послідовного алгоритму) на підграфи $G_{1}\left(X_{1}, U_{1}\right), G_{2}\left(X_{2}, U_{2}\right), \ldots, G_{N}\left(X_{N}, U_{N}\right)$, що задовольняють обмеження. Основу цих алгоритмів складає ітераційний процес обміну місцями елементів, що належать до різних підграфів. Обмін елементів проводять 3 метою оптимізації вибраного показника якості компонування, зазвичай кількості зовнішніх зв'язків. Якщо припустити, що вершина $x_{m}$ належить підграфу $G_{i}\left(X_{i}, U_{i}\right)$, а вершина $x_{l}-$ підграфу $G_{j}\left(X_{j}, U_{j}\right)$, то зміну кількості ребер $\Delta r_{m l}$, що з'єднують $G_{i}$ і $G_{j}$ в результаті перестановки вершин}


$x_{m}, x_{l}\left(x_{m} \rightarrow G_{j}, x_{l} \rightarrow G_{i}\right)$, можна подати у вигляді:

$\Delta r_{m l}=\left(\sum_{k \in I_{j}} S_{m k}-\sum_{p \in I_{i}} S_{m p}\right)+\left(\sum_{p \in I_{i}} S_{l p}-\sum_{k \in I_{j}} S_{l k}\right)-2 S_{m l}$

де $I_{i}$ i $I_{j}-$ множини індексів вершин, що належать відповідно $X_{i}$ і $X_{j}$;

\section{$S_{i j}$ - елементи матриці суміжності.}

Перестановка доцільна в тому випадку, якщо $\Delta r_{m l}>0$, причому ефективність пї тим вища, чим більшим є значення $\Delta r_{m l}$.

Процес перерозподілу вершин закінчується або під час отримання локального екстремуму критерію оптимізації, який задовільняв би розробника, або після виконання заданої кількості ітерацій.

Для ітераційних алгоритмів другого типу початковим варіантом $\epsilon$ розбивання графа на дві частини. Спочатку здійснюють парні чи групові перестановки вершин із цих частин для мінімізації кількості зв'язків між ними. Потім почергово розглядають кожну 3 частин i, y свою чергу, розбивають на два підграфи з подальшою мінімізацією кількості зв'язків між ними перестановкою вершин. Цей процес продовжується до того часу, поки не буде отримане задане розбивання.

Процес «розбивання» графа $G(X, U)$ на $N$ підграфів еквівалентний розбиванню матриці суміжності $S=\left\|S_{i j}\right\|_{n * n}$ на $N \cdot N$ підматриць $S_{k p}$, $k=\overline{1, N} ; p=\overline{1, N}$. При цьому парний обмін вершин $x_{m}$ і $x_{l}$ відповідає перестановці відповідних рядків і стовпців матриці $S$. Оскільки сума елементів будьякої недіагональної підматриці $S_{k p}(k \neq p)$ визначає кількість ребер, які з'єднують підграфи $G_{k}$ i $G_{p}$, то оптимальний ітераційний процес парних перестановок полягає в пошуку на кожній ітерації таких перестановок рядків і стовпців матриці $S$, при яких максимізується сума елементів у діагональних підматрицях $S_{k k}, k=\overline{1, N}$, що відповідає мінімізації кількості з'єднувальних ребер.

У тому випадку, якщо $N \cdot n_{\max }>n, \quad-$ максимально допустима кількість вершин в окремо взятому графі, у початковий граф $G(X, U)$ вводять додаткові ізольовані вершини і переходять до графа $G\left(X^{*}, U\right), \quad$ в якому $\quad X^{*}=X U X_{f}, \quad$ остаточна множина вершин, де $X_{f}$-множина додаткових вершин, причому $\left|X_{f}\right|=N \cdot n_{\max }-n$.

Розглянемо мультиграф, зображений матрицею суміжності. За допомогою ітераційного алгоритму виконаємо оптимальне за критерієм мінімуму зовнішніх зв'язків розбивання графа $G(X, U)$ на три підграфи з кількістю вершин $\left|x_{i}\right| \leq 3$.

У вихідний граф $G(X, U)$ для виконання вимоги однакової кількості вершин у кожному із підграфів, що формуються, введемо додаткову ізольовану вершину $x_{9}$. Отримаємо граф $G\left(X^{*}, U\right) \quad 3$ матрицею суміжності:

$$
\begin{array}{c||ccccccccc||} 
& x_{1} & x_{2} & x_{3} & x_{4} & x_{5} & x_{6} & x_{7} & x_{8} & x_{9} \\
x_{1} & 0 & 0 & 1 & 1 & 0 & 3 & 0 & 1 & 0 \\
x_{2} & 0 & 0 & 2 & 0 & 1 & 0 & 1 & 0 & 0 \\
x_{3} & 1 & 2 & 0 & 0 & 0 & 0 & 1 & 0 & 0 \\
x_{4} & 1 & 0 & 0 & 0 & 2 & 0 & 0 & 0 & 0 \\
x_{5} & 0 & 1 & 0 & 2 & 0 & 1 & 0 & 1 & 0 \\
x_{6} & 3 & 0 & 0 & 0 & 1 & 0 & 0 & 2 & 0 \\
x_{7} & 0 & 1 & 1 & 0 & 0 & 0 & 0 & 1 & 0 \\
x_{8} & 1 & 0 & 0 & 0 & 1 & 2 & 1 & 0 & 0 \\
x_{9} & 0 & 0 & 0 & 0 & 0 & 0 & 0 & 0 & 0
\end{array}
$$

Виконаємо початкове «розбивання» графа $G(X, U)$ на підграфи $G_{1}\left(X_{1}, U_{1}\right), G_{2}\left(X_{2}, U_{2}\right) ; G_{3}\left(X_{3}, U_{3}\right)$ таким чином: $X_{1}=\left\{x_{1}, x_{2}, x_{3}\right\}, X_{2}\left\{x_{4}, x_{5}, x_{6}\right\}, X_{3}\left\{x_{7}, x_{8}, x_{9}\right\}$.

Відповідно до цього розбиваємо матрицю суміжності на три підматриці третього порядку (недіагональні підматриці задають зв'язки між підграфами, а діагональні - внутрішні зв'язки в кожному підграфі. Загальна кількість зв'язків для такого розбивання дорівнює 13.

Для кожного елемента визначимо сумарну кількість його внутрішніх зв'язків, а також сумарну кількість зв'язків 3 елементами кожного окремого підграфа (зовнішніх зв'язків). Різницю кількості зовнішніх і внутрішніх зв'язків припишемо до рядка матриці, що розглядаємо, у відповідні даній парі підграфів стовпці. 


\begin{tabular}{c||ccc|ccc|ccc||c|c|c}
$x_{1}$ & $x_{1}$ & $x_{2}$ & $x_{3}$ & $x_{4}$ & $x_{5}$ & $x_{6}$ & $x_{7}$ & $x_{8}$ & $x_{9}$ & $G_{1}-G_{2}$ & $G_{1}-G_{3}$ & $G_{2}-G_{3}$ \\
$x_{1}$ & 0 & 0 & 1 & 1 & 0 & 3 & 0 & 1 & 0 & 3 & 0 & - \\
$x_{2}$ & 0 & 0 & 2 & 0 & 1 & 0 & 1 & 0 & 0 & -1 & -1 & - \\
$x_{3}$ & 1 & 2 & 0 & 0 & 0 & 0 & 1 & 0 & 0 & -3 & -2 & - \\
$x_{4}$ & 1 & 0 & 0 & 0 & 2 & 0 & 0 & 0 & 0 & -1 & - & -2 \\
$x_{5}$ & 0 & 1 & 0 & 2 & 0 & 1 & 0 & 1 & 0 & -2 & - & -2 \\
$x_{6}$ & 3 & 0 & 0 & 0 & 1 & 0 & 0 & 2 & 0 & 2 & - & 1 \\
$x_{7}$ & 0 & 1 & 1 & 0 & 0 & 0 & 0 & 1 & 0 & - & 1 & -1 \\
$x_{8}$ & 1 & 0 & 0 & 0 & 1 & 2 & 1 & 0 & 0 & - & 0 & 2 \\
$x_{9}$ & 0 & 0 & 0 & 0 & 0 & 0 & 0 & 0 & 0 & - & 0 & 0
\end{tabular}

Знайдемо пару вершин $x_{m}$ i $x_{l}$, перестановка яких приведе до максимального скорочення кількості зв'язків між підграфами. Для цього необхідно, щоб величина $\Delta r_{m l}$ була додатною, тому різниця кількості зовнішніх і внутрішніх зв'язків для однієї із вершин має бути додатною. Можливими претендентами для обміну будуть пари $\left(x_{1}, x_{4}\right),\left(x_{1}, x_{5}\right),\left(x_{1}, x_{6}\right),\left(x_{1}, x_{7}\right),\left(x_{6}, x_{8}\right),\left(x_{6}, x_{9}\right)$.

Використовуючи вираз (1), отримаємо:

$\Delta r_{14}=0 ; \Delta r_{15}=1 ; \Delta r_{16}=-1 ; \Delta r_{17}=1 ; \Delta r_{68}=-1 ; \Delta r_{69}=1$.

Обміни $\left(x_{1}, x_{5}\right),\left(x_{1}, x_{7}\right),\left(x_{6}, x_{9}\right)$ є рівноцінними $\mathrm{i}$ зменшують кількість зв'язків між підграфами на одиницю. Виберемо для обміну вершини $x_{1}$ i $x_{7}$, які належать підграфам $G_{1}$ i $G_{3}$. У перестановки першого та сьомого рядків і відповідно стовпців отримаємо матрицю $S^{\prime}$, ізоморфну даній. Приймемо розподіл вершин за початковий і виконаємо другу ітерацію.

\begin{tabular}{|c|c|c|c|c|c|c|c|c|c|c|}
\hline & $\| \begin{array}{ll}x_{7} & x\end{array}$ & $\begin{array}{ll}x_{2} & x_{3}\end{array}$ & $x_{4}$ & $x_{5}$ & $x_{6} \mid x_{1}$ & $\begin{array}{ll}x_{1} & x_{8}\end{array}$ & $x_{9}$ & $G_{1}-G_{2}$ & $G_{1}-G_{3}$ & $G_{2}-G_{3}$ \\
\hline$x_{7}$ & 0 & 1 & 0 & 0 & \begin{tabular}{l|l}
0 & 0
\end{tabular} & 1 & 0 & -2 & -1 & - \\
\hline$x_{2}$ & 1 & 0 & 0 & 1 & \begin{tabular}{l|l}
0 & 0
\end{tabular} & 0 & 0 & -2 & -3 & - \\
\hline$x_{3}$ & $\mid 1$ & 2 & 0 & 0 & \begin{tabular}{l|l}
0 & 1
\end{tabular} & 0 & 0 & -3 & -2 & - \\
\hline & 0 & 0 & 0 & 2 & \begin{tabular}{l|l}
0 & 1
\end{tabular} & 0 & 0 & -2 & - & -1 \\
\hline & 0 & 1 & 2 & 0 & \begin{tabular}{l|l}
1 & 0
\end{tabular} & 1 & 0 & -2 & - & -2 \\
\hline$x_{6}$ & 0 & 0 & 0 & 1 & \begin{tabular}{l|l}
0 & 3
\end{tabular} & 2 & 0 & -1 & - & 4 \\
\hline$x_{1}$ & 0 & 0 & 1 & 0 & \begin{tabular}{l|l}
3 & 0
\end{tabular} & 1 & 0 & - & 0 & 3 \\
\hline$x_{8}$ & $\mid 1$ & 0 & 0 & 1 & \begin{tabular}{l|l}
2 & 1
\end{tabular} & 0 & 0 & - & 0 & 2 \\
\hline$x_{9}$ & 0 & 0 & 0 & 0 & & 0 & 0 & - & 0 & 0 \\
\hline
\end{tabular}

Можливі варіанти обміну:

$$
\begin{aligned}
& \left(x_{1}, x_{4}\right),\left(x_{1}, x_{5}\right),\left(x_{1}, x_{6}\right),\left(x_{8}, x_{6}\right),\left(x_{8}, x_{4}\right),\left(x_{8}, x_{6}\right),\left(x_{9}, x_{6}\right), \\
& \Delta r_{14}=0 ; \Delta r_{15}=1 ; \Delta r_{16}=1 ; \Delta r_{84}=1 ; \Delta r_{86}=2 ; \Delta r_{96}=4 .
\end{aligned}
$$

Обмін $\left(x_{9}, x_{6}\right)$ зменшує кількість зв'язків між підграфами на чотири. Переставивши відповідно i рядки, і стовпці матриці $S^{\prime}$, отримаємо матрицю $S^{\prime \prime}$, для якої продовжимо ітераційний процес.

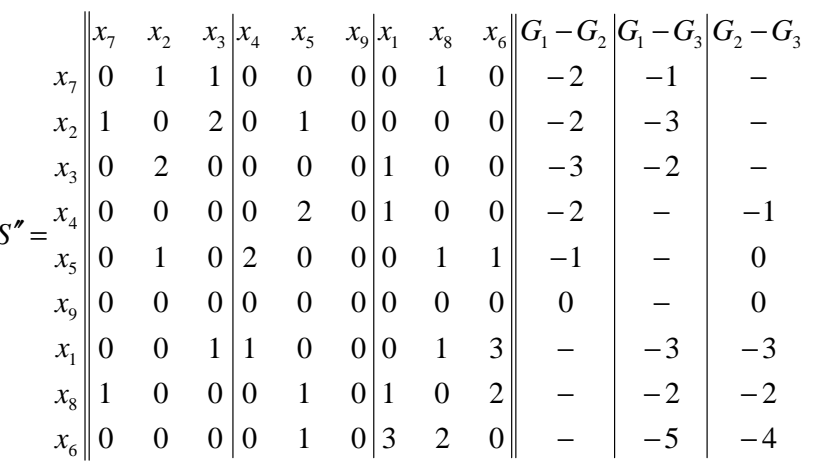

Помітно, що подальші перестановки не можуть покращити отримане розбивання, тому кінцевий варіант компонування такий:

$$
X_{1}=\left\{x_{2}, x_{3}, x_{7}\right\}, X_{2}=\left\{x_{4}, x_{5}\right\}, X_{3}=\left\{x_{1}, x_{6}, x_{8}\right\} .
$$

Оскільки на кожному кроці вибирається така пара вершин, перестановка яких мінімізує число зовнішніх ребер, то в остаточному підсумку отримаємо локальний мінімум можливого числа з'єднувальних ребер. Йому відповідають вісім зв'язків між підграфами графа.

\section{Висновки}

Ітераційні алгоритми компонування забезпечують високу якість розбивання графа на підграфи, задовольняючи вимоги мінімуму зовнішніх зв'язків, однак потребують больших витрат часу, ніж послідовні алгоритми. Підвищення точності рішення досягається значним ускладненням алгоритму, що полягає в перестановці груп вершин графа. Для скорочення часу ітерацій слід використовувати послідовні методи формування підграфів, а також групові перестановки пар вершин, які взаємно не перетинаються.

\section{Список використаних джерел}

1. Курейчик, В. М. Математическое описание конструкторского и технологического проектирования с применением САПР [Текст]: учеб. для вузов / В. М. Корнейчук. - М. : Радио и связь, 1990. - 352 с.

2. Корольова, Я. Ю. Використання послідовного алгоритму компонування в конструкціях мультимедіа [Текст] / Я. Ю. Корольова, I. С. Бєліков // Інформаційно-керуючі системи на залізничному транспорті. - 2018. - № 6. - С. 22-25. 
3. Саломатин, В. А. Последовательный алгоритм компоновки конструктивных элементов на основе задания схемы в виде гиперграфа [Текст] / В. А. Саломатин, В. Н. Струнилин // Наукові праці ДонНТУ. Сер. Інформатика, кібернетика та обчислювальна техніка. - 2009. - № 10 (153). C. 198-201.

4. Isomorphism between Cayley (di)graphs [Text] / J. G. Fernandes, R. E. Giudici // Discrete Mathematics. - 2005. - № 305. - P. 361-364.

5. Algebraic Graph Theory [Text] / N. Biggs // Cambridge University Press, Cambridge, 1974.

\section{Мирошник М. А., Королёва Я. Ю. Итерационные алгоритмы компоновки В конструкциях мультимедиа.}

Аннотация. На основе теоретического обобщения и работ в области алгоритмизации типовых задач конструкторского проектирования в автоматизированных системах разработан итерационный алгоритм компоновки элементов в конструкциях мультимедиа. В качестве формальной математической модели использована теория графов, где каждому конструктивному элементу схемы соответствует вершина, а электрическим связям ребра графа. Все это позволяет абстрагироваться от конкретных электрических схем и переходить к их математическим моделям - графам, разрабатывать эффективные методы поиска оптимальных конструктивных решений.

Ключевые слова: электрическая схема, алгоритм, итерация, мультиграф, разбивание графа, матрица смежности, оптимальность.

\section{Miroshnyk M.A., Koroleva Y.U. Interaction algorithms compositing in multimedia constructions.}

Abstract. On the basis of theoretical generalization and work in the field of algorithmization of typical design engineering problems in automated systems, the authors have developed an iterative algorithm for the layout of elements in multimedia designs. As a formal mathematical model, graph theory was used, where each structural element of the scheme corresponds to a vertex, and to electrical connections - edges of the graph. All this allows us to abstract away from specific electrical circuits and move on to their mathematical models - graphs - to develop effective methods for finding optimal design solutions. The task of the iterative layout algorithm is to select some initial breakdown of the graph with subsequent permutations of vertices or groups from one subgraph to another in order to minimize the number of external edges or maximize the number of internal edges. Analyzing the obtained results, it can be said that the layout algorithms provide a high quality of breaking the graph into subgraphs satisfying the requirements of a minimum of external links, but they require a lot of time than sequential algorithms. Improving the accuracy of the solution is achieved due to a significant complication of the algorithm, which consists in rearranging groups of vertices of the graph. To reduce the iteration time, you should use consistent methods of subgraph formation, as well as group permutations of pairs of vertices that do not intersect each other.

Keywords: electrical circuit, algorithm, iteration, multigraph, graph splitting, adjacency matrix, optimality.

Надійшла 05.03.2019 p.

Мірошник Марина Анатолї̈вна, доктор технічних наук, професор кафедри спеціалізованих комп'ютерних систем, Украӥнський державний університет залізничного транспорту, Харків, Україна. E-mail: miroshnyk@kart.edu.ua ORCID ID: http://orcid.org/0000-0002-2231-2529

Корольова Яна Юріївна канд. техн. наук, доцент кафедри мультимедійних інформаційних технологій $i$ систем, Національний технічний університет «Харківський політехнічний інститут». E-mail: Yanakoroleva815@gmail.com. ORCID ID: http://orcid.org/0000-0002-7203-5603

Miroshnyk Maryna Anatolijvna., doctor of technical science, professor of the Department of Computer Systems Ukrainian State University of Railway Transpor, Kharkiv, Ukraine. E-mail:miroshnyk@kart.edu.ua http://orcid.org/0000-0002-2231-2529

Koroleva Yana Urievna, Ph.D., Multimedia information technologies and systems, National Technical University «Kharkov Polytechnic Institute», Kharkiv, Ukraine. E-mail: Yanakoroleva815@gmail.com ORCID ID: http://orcid.org/0000-0002-7203-5603 